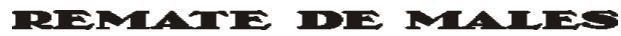

Campinas-SP, v. 38, n. 1, pp. 240-267, jan./jun. 2018

\title{
O DESAFIO DO TIMOR-LESTE ATUAL: EM BUSCA DE UMA IDENTIDADE NACIONAL LIGADA À LÍNGUA PORTUGUESA
}

\author{
Hélio José Santos Maia ${ }^{1}$ \\ Maria Helena da Silva Carneiro²
}

\begin{abstract}
Resumo: Produto de extensa pesquisa sobre educação em Timor-Leste, este artigo apresenta um recorte sobre os desafios da implantação da língua portuguesa naquele país, que a colocou como língua oficial de instrução na sua Constituição. O Timor é considerado um país transcontinental por apresentar seus domínios tanto no continente asiático, em sua porção norte, sob a influência do Pacífico, quanto na Oceania, em sua porção sul, ligada ao Oceano Índico. Antiga colônia portuguesa, provavelmente a menos prestigiada do Império Português ultramar, possui uma história eivada de desafios em busca de sua autonomia como nação. O objetivo do trabalho é apresentar, por meio das narrativas de antigos governadores portugueses no Timor do período colonial, Afonso de Castro (1824-1885) e Teófilo Duarte (1898-1958), as dificuldades do empreendimento colonial português naquelas terras frente à pluralidade linguística e cultural delas, ao espírito arredio dos seus habitantes em relação ao domínio português e aos obstáculos, conferidos pela distância da metrópole, para implantação definitiva da empresa colonial. Para isso, empreendeu-se pesquisa bibliográfica a livros e documentos na Biblioteca do Programa de Pós-Graduação e Pesquisa (PPGP) da Universidade Nacional de Timor Lorosa'e (UNTL), em Díli, Timor-Leste, assim como à Biblioteca do Instituto Nacional de Formação de Docentes e Profissionais da Educação (Infordepe), e entrevistas a professores, a formadores de professores e a estudantes no país. Como resultados, é possível identificar a dificuldade na implantação da língua portuguesa pela via educacional, em função da ausência de imersão nessa língua no espaço escolar, da grande oferta de línguas maternas para a comunicação cotidiana, do fortalecimento do movimento pela implantação de línguas maternas na escolarização inicial das crianças, ao mesmo tempo em que aponta
\end{abstract}

1 Docente da Faculdadede Educação, Departamento de Métodos e Técnicas da Universidade de Brasília (FE/MTC/UnB): heliomaia@unb.br.

2 Docente do Programa de Pós-Graduação em Educação da Faculdade de Educação da Universidade de Brasília (PPGE/UnB): mhsilcar@unb.br. 
a possibilidade de aquisição da língua portuguesa por seu povo pelo alcance do ciclo completo de escolarização até o nível superior.

Palavras-chave: Timor-Leste; colônia portuguesa; língua portuguesa.

\section{INTRODUÇÃO}

As narrativas construídas pelos agentes do Império Português de além-mar a partir do século XV representam grande façanha do engenho humano em dois sentidos: primeiro em função do empreendimento em si das Grandes Navegações, do qual Portugal foi vanguarda, e, em segundo, a produção literária gerada na ação desbravadora de mares e territórios de povos e culturas distintos, e na administração com configurações diversas adaptadas para povos diferentes.

Entreas histórias variadas das diferentes configurações queemergiram da interação de Portugal com os povos dominados, possivelmente a do Timor-Leste representa uma das menos difundidas e conhecidas. Existe já uma historiografia, ainda que tímida, na qual é possível reconstituir sentidos que permitem o entendimento das conformações do Timor-Leste atual.

Nesse sentido, o presente trabalho tem a pretensão, embora de maneira superficial, de apontar aspectos da história do Timor-Leste do século XX por meio de documentos escritos por antigos governadores portugueses do Timor, que remontam ao final do século XIX, e de documentos diversos da história mais recente, posterior à Segunda Grande Guerra Mundial no século XX. Para sua realização, promoveu-se pesquisa a documentos e livros disponíveis na Biblioteca do Programa de Pós-Graduação e Pesquisa (PPGP) da Universidade Nacional de Timor Lorosa'e (UNTL), em Díli, Timor-Leste, e à Biblioteca do Instituto Nacional de Formação de Docentes e Profissionais da Educação (Infordepe) desse país, além de entrevistas a professores, a formadores de professores e a estudantes da escola básica, como parte de pesquisa de doutoramento de um dos autores deste trabalho.

O Timor-Leste localiza-se geograficamente no sudeste asiático e representa a porção oriental de uma ilha cuja porção ocidental, Nusa Tengara, pertence à Indonésia, sendo o norte banhado pelo Mar de Banda, ligado ao Oceano Pacífico, e o sul, pelo Mar de Timor, localizado no Oceano Índico. Nos aspectos biológicos, etnográficos e culturais, está mais relacionado às ilhas vizinhas da Melanésia do que da Ásia propriamente dita, o que o posicionaria na Oceania. 
Dessa forma, pode-se considerá-lo uma nação transcontinental. De colonização portuguesa, apresenta história instigante no âmbito dos projetos coloniais lusitanos no Pacífico e na Oceania.

Embora se pontuem introdutoriamente narrativas de Castro (1867) do período colonial até o século XIX, as investigações neste trabalho se centram nas narrativas de Duarte (1944).

\section{A OCUPAÇÃO BRANCA DE TIMOR, RELATADA POR TEÓFILO DUARTE ATÉ A PRIMEIRA METADE DO SÉCULO XX}

O livro As possessões portuguesas na Oceania, publicado em 1867, de Afonso de Castro (1824-1885), governador português do TimorLeste nomeado para o cargo em 1858 e tendo permanecido até 1863 , provavelmente se constitui em uma das poucas obras do período colonial até o século XIX sobre o Timor-Leste. Diga-se de passagem, o período colonial foi iniciado em 1511, tendo se estendido até 1975, por ocasião da saída das tropas portuguesas em função da Revolução dos Cravos, que ocorria em Portugal, quando o Timor-Leste proclamou sua independência unilateral, que durou nove dias, sendo em seguida invadido pela Indonésia. Nessa obra, a narrativa, adotando a ótica do colonizador, está embasada em relatos orais, alguns documentos da marinha lusitana e outros documentos dos arquivos do próprio Timor. Arquivos que pertenceram a Goa forneciam a Castro (1867) alguns esclarecimentos sobre o Timor, mas, ainda assim, não eram de confiança, pois, segundo ele, entre uma ou outra verdade se introduziu muita falsidade.

Na sua narrativa, o autor enfatiza o desprezo que Portugal havia dado àquelas terras, haja vista a ação exitosa da empresa portuguesa nas outras colônias de além-mar, mas salienta que as fontes não são tão confiáveis assim e informa que apresentará sobre o Timor simples conjecturas, em vez de narrativas fiéis, recorrendo à tradição para o conhecimento de fatos que os arquivos deveriam mostrar. Salienta ainda que omitirá tudo aquilo que sua razão rejeitar como fabuloso, procurando discriminar o verdadeiro do falso. Porém, a obra funcionou como um ponto de partida para que outros cronistas, sobretudo os do século XX, pautassem suas narrativas nela.

Nesse sentido, já no século $\mathrm{XX}$, dignas de nota são as narrativas de Teófilo Duarte (1898-1958), outro português que governou o Timor-Leste, nos anos de 1927 a 1929. Na obra Ocupação e colonização branca 
de Timor, Duarte afirma que a ação de povoamento do branco português em Timor foi a mais tardia dentre as colônias do império. Constata, nesse livro, que "em 1929 era flagrante a ausência quase absoluta de brancos que não fossem funcionários, somando estes um total de 340 apenas, contra 690 indivíduos mestiços" (DUARTE, 1944, p. 22).

Após considerações sobre a exígua presença do branco português e sobre a exploração de culturas agrícolas como café, cacau e borracha - a cargo dos herdeiros de um ex-governador, Celestino da Silva (1849-1911), que governou o Timor de 1894 a 1908 e cuja produção destinava-se à exportação para as Índias Holandesas, Duarte (1944) afirma que o empreendimento agrícola contava administrativamente com pouquíssimos brancos e que o trabalho braçal era empenhado pelos "indígenas". O autor justifica os fatores que levaram a essa escassa ocupação portuguesa em Timor:

Como se vê, o esforço desenvolvido em Timor durante séculos, até o ano de 1929, não pode ombrear com o constatado em qualquer das nossas outras colônias. E porquê? [Sic] Vejamos algumas das principais causas do fato, sem termos a pretensão de lhe encontrar uma explicação completa. Timor é a colônia portuguesa que se encontra mais afastada da metrópole - e com uma grande diferença - se não entramos em linha de conta com Macau. Natural era pois que, através dos séculos, a nossa atenção se concentrasse principalmente naquelas que nos ficavam mais próximas, sendo por isso mais frequentes os contatos com elas, mais conhecidos os seus recursos, e em que havia maiores possibilidades de fiscalização, quer através das entidades governamentais, quer das simples particulares que nelas empregavam as suas atividades. Ainda hoje, apesar da rapidez das comunicações, uma viagem normal para aquela nossa colônia da Insulíndia demora quarenta e cinco dias, enquanto que para a Guiné se faz em oito, e para Angola em vinte. (DUARTE, 1944, pp. 23-24)

A distância, como primeiro argumento de Duarte, pesou para o pouco empenho português em investimento no Timor e sua colonização, nos moldes do ocorrido nas outras colônias. Ademais, é espantoso que em 1944, época da publicação do livro acima mencionado, ainda se levasse quarenta e cinco dias de navio para chegar ao Timor-Leste. Para se perceber, transportando para o tempo contemporâneo, esse distanciamento no aspecto geográfico, a viagem aérea atual para o Timor-Leste, partindo do Brasil, comparada com outros destinos mais afeitos aos brasileiros, como Estados Unidos ou Europa, é assustadora e dura em média 30 horas de voo, incluindo as intermináveis escalas, seja indo pelo Pacífico, pela Austrália, ou pelo Atlântico, cruzando a África até o Qatar e Bali, na Indonésia. Não é de admirar que a distância Portugal-Timor 
no período colonial desanimasse aos mais destemidos empreendedores lusitanos.

Nas palavras de Duarte (1944, p. 24),

Este fator, o da distância, trazia pois como consequência, o pouco interesse pela colônia, que era conhecida pouco e mal das instâncias oficiais, e desconhecida quase em absoluto das entidades que se dedicavam a atividades coloniais. Uma pequena ilha perdida nos confins das Îndias Orientais, apenas conhecida pelo precioso mas escasso comércio de sândalo, pouca atenção podia merecer ao país que possuía tantos e tão valiosos troféus, como a costa da Guiné, a Índia e o Brasil.

Outros fatores aventados por Duarte (1944, p. 24) sobre o desinteresse português, quando o assunto era o Timor, centram-se na tradição de aceitação de que aquela "terra apresentava um clima horrível, que matava ou inutilizava fatalmente, o que provinha do desconhecimento quase absoluto do interior que era magnífico". Associe-se a isso a insubmissão dos nativos que acarretava frequentes chacinas dos raros europeus que por dever de ofício se faziam presentes no Timor e, por fim, a falta de comodidades quase absoluta em uma colônia quase toda por ocupar. Segundo Duarte (1944, p. 25),

Tudo isso criava uma lenda em volta de Timor, que fazia com que a colocação ali de qualquer funcionário fosse considerada como o pior castigo que se lhe podia aplicar. Como admirarmo-nos pois que os simples particulares nem sequer pensassem em tal colônia, quando tratavam de escolher uma para onde se expatriassem à procura de fortuna, ou pelo menos duma conveniente situação que lhes assegurasse um regular passadio? Timor, a odiada, a desprezada era a última colônia a atrair atenção dos portugueses. Ela era para nós, o que tantas outras representavam para países colonizadores de maiores recursos: uma ameaça para degredados e maus funcionários.

Posterior à visão de Afonso de Castro, que publicara seu livro em 1867, Teófilo Duarte, na sua publicação de 1944, estabelece que a situação de esquecimento à qual o Timor ficou relegado durou até o ano de 1894, quando assumiu o governo da colônia Celestino da Silva, apelidado de "Rei do Timor" (XIMENES BELO, 2013, p. 71), que era naquela altura major de cavalaria, mas que, por ocasião da sua morte em 1911, tinha se tornado general, conselheiro de Estado, comendador da Torre e Espada, além de possuir a medalha de ouro do valor militar, a medalha de ouro da rainha D. Amélia e a medalha de ouro de serviços relevantes no Ultramar. Essas honrarias se deveram aos altos serviços prestados à Pátria por ocasião da sua passagem pelo governo do Timor. 
Ao delinear a situação do Timor no período imediatamente anterior à sua posse, o cronista Duarte (1944) coloca os domínios portugueses no Timor como mais teóricos do que reais, já que se mantinha à custa de combinações políticas com os régulos, nem sempre amigáveis, e que as ações rebeldes das populações locais não passavam por nenhuma reprimenda ou ato corretivo da parte de Portugal. Mais uma vez, percebe-se nas narrativas desses pioneiros cronistas da história do Timor, ainda que sob a ótica portuguesa, que os timorenses gozavam de liberdades nos seus domínios e que a gerência de Portugal sobre o território não se fazia nos mesmos rigores observados em outras colônias.

As forças de ocupação do território se reduziam a poucos oficiais, que esparsamente eram distribuídos pelo litoral, responsáveis pela vigilância do território com o apoio de pouquíssimos soldados, que, no dizer de Duarte (1944, p. 27), "durante quase todo o ano permaneciam no hospital ou nos presídios para onde os arrastavam os seus vícios e o seu caráter de incorrigíveis vindos de Macau”. Mesmo assim, durante as flutuações de "humor" das populações do interior do Timor, esses poucos soldados se refugiavam em Díli, permanecendo mais protegidos na cidade, esperando as vagas rebeldes se pacificarem para a retomada de seus postos, de onde se depreende que o interior se encontrava sem um comando, ou alguma centralidade, que conferisse soberania de Portugal naquelas terras.

Por esses achados, é perfeitamente possível entender o grau de autonomia que a população timorense guardou desse período colonial, na manutenção do seu plurilinguismo - Ximenes Belo (2013, p. 39) menciona 17 línguas autóctones em Timor, a saber: Tétum, Galoli, Idá, Macassai, Uaimá, Cairuhi, Dagadá, Meidique, Vauneque, Dagadá enaneti, Caruhy, Bunac, Vaqueno, Toco-dede, Fataluku, Quemac e Mambae - e dos seus valores culturais. Ainda que os régulos aceitassem a sanção pelo governo português das eleições que os sagravam mandatários, o faziam como prestação de vassalagem a Díli, uma formalidade que não implicava custo algum cumprir, mas cuja cerimônia espetaculosa, de certa forma, os atraía mais do que o significado em si de obrigações devidas.

Embora seja natural pensar-se em uma unidade étnica de um só povo no território timorense naquele período, o certo é que eram reinos independentes e quase sempre em contendas, disputando recursos, como terras e animais, e que por essas disputas se envolviam em batalhas cruentas, quase sempre produzindo dezenas de mortos e animais confiscados pelos vencedores. Mas, fora isso, as populações continuavam 
organizadas em seus territórios com certo grau de apaziguamento até que novos conflitos irrompessem pelas mesmas razões ou por outros motivos. Ou seja, não havia, de todo, a perspectiva de domínio e extermínio dos vencidos.

Nas palavras de Duarte (1944, p. 29),

As diversas tribos agremiadas em reinos mais ou menos importantes passavam os anos em guerras intestinais cujo fundamento era o desejo de roubarem aos vizinhos os seus gados, os produtos agrícolas, as mulheres e as terras. Não havia progresso compatível com tal desordem que era extensiva às centenas de milhares de timores, e ora se viam lutas formidáveis entre vinte e trinta mil homens de cada partido, ora elas se resumiam a pequenos mas numerosíssimos combates de centenas de guerreiros.

Essas contendas podem ser analisadas de pontos de vista diferentes, a saber: para os comerciantes eram lucrativas, já que auferiam largos proventos em decorrência da venda de pólvora e de armas. Para os timorenses e sua índole guerreira, era preferível a posse do butim das terras pilhadas do que poder arrancar da terra com o suor do seu trabalho, mas, para Portugal, embora vergonhosa, a situação era inevitável diante da escassa ocupação exercida em todos os sentidos. Superar essa condição seria possível somente à custa de pesados sacrifícios com expedições e permanência de grandes contingentes.

Outro aspecto a analisar liga-se ao fato de que as lutas ocorriam entre populações do próprio Timor, raramente entre os timorenses e os poucos portugueses. Essa paz era mantida pelos pactos de vassalagem que eram prestados entre os governantes timorenses e os representantes da autoridade portuguesa. Muitas vezes, diante de contendores dos reinos locais, os governantes portugueses funcionaram como árbitros para avaliar quem eram os vencidos e os vencedores. Em caso da não aceitação das definições portuguesas, as lutas continuavam, e o papel de Portugal era meramente teórico e impotente para a resolução dos conflitos.

Nesse sentido, a importância de Celestino da Silva como governador do Timor por quatorze anos, a partir de 1894, tornou-se grande, pois foi o primeiro a perceber que a evolução econômica do Timor e da empresa colonial só começaria a ocorrer quando essas contendas frequentes cessassem. Assim, começou uma obra de ocupação gradual e contínua do território do Timor por meio de ação de colonização propriamente dita. Entre suas ações mais emblemáticas estava a pacificação de povos em guerra por ação diplomática, ou seja, o encaminhamento de diplomatas 
portugueses aos régulos contendores que os presenteavam com armas e trabalhos na limpeza dos cafezais e outras lavouras daquelas terras, bem como com benfeitorias de ordem geral, em troca do restabelecimento da paz entre os guerreiros. Dessa forma, a pacificação ocorria aos poucos sem a necessidade de força ou interferência violenta por parte de Portugal. Duarte (1944, p. 31) aponta que o oficial português diplomata

\begin{abstract}
deixava de ser o severo comandante de tropas e colunas, tudo raziando, devastando, e fazendo consistir a sua glória no número de vítimas caídas, para se transformar no colonizador, que após rudes combates a que o obrigava a índole insubmissa dos povos que lhe mandavam bater, procurava encaminhálos no sentido da riqueza e civilização. Ampliação de plantações, abertura de estradas, limpeza de caminhos etc., tudo isso eram trabalhos que faziam do Comandante militar ou de posto, o guia de todos aqueles que na véspera tratara com a severidade de um dominador.
\end{abstract}

As sábias instruções de Celestino da Silva revelaram-se como uma espécie de "manual de colonização", no qual a ação diplomática, o absoluto conhecimento das línguas locais, bem como o levantamento das populações e seus hábitos culturais, os cuidados ambientais nas terras de cada reino, os cuidados com as lavouras de café e as de subsistência representaram um modo de ação avançado e particular da prática colonial que Portugal experimentava na direção do Timor. Duarte (1944) informa sobre as instruções dadas por Celestino aos seus comandados portugueses, as quais não deixam dúvidas sobre esses avanços na forma administrativa de conduzir o Timor:

É absolutamente indispensável que os comandantes militares subalternos se instruam sobre a língua dos indígenas, seus usos e costumes; que conheçam dentro da área da sua jurisdição, todos os caminhos ainda os mais recônditos, todas as povoações, todos os habitantes, os chefes indígenas e suas famílias; que lhes não passe despercebida a saída para fora, ou a entrada de qualquer; que tenham perfeito conhecimento de todos os casamentos, óbitos e nascimentos; que façam um arrolamento exato da população; que não deixem derrubar florestas cuja destruição possa exercer influência nas condições climáticas; que não deixem despir de arvoredo, as nascentes de água; que conservem sempre em bom estado os caminhos vicinais; que vigiem se os indígenas conservam em bom estado de limpeza as suas plantações de café, e se fazem cultivos suficientes para a sua alimentação; se há transgressão dos regulamentos de polícia rural de mercados; se o contrabando se exerce; se são respeitados os regulamentos que regem a venda do sal; e enfim se há quaisquer causas que possam vir a alterar o sossego público. É isto o que os Senhores comandantes militares têm o dever de exigir dos seus subalternos, além do mais que especialmente lhes determinem, por isso, que das faltas, dos 
desleixos, da incúria deles, são os primeiros responsáveis. (DUARTE, 1944, p. 32)

Mas, no meio dessas ações diplomáticas que amansavam os ímpetos guerreiros timorenses, o governador Celestino da Silva fortalecia os comandos militares estratégicos em torno de Díli, a capital, e aos poucos avançava sobre o território, aumentando o contingente militar e intervindo em contendas inter-reinos sempre que provocado. Desse modo, pelo uso da força foi também expandindo seus domínios entre aquelas populações beligerantes. Estrategista militar que era, Celestino obteve sucesso enquanto estabeleceu um consórcio entre diplomacia e ação militar e foi avançando nas conquistas do território. Em uma situação ocorrida em 1895, oficiais subalternos não atenderam as recomendações estratégicas estabelecidas, havendo a violação dos espaços dos régulos locais e contra suas famílias. Diante disso ocorreu verdadeira tragédia com muitas perdas humanas de ambos os lados. Decapitações e incêndios de benfeitorias marcaram essas lutas cruentas, o que nos permite entender o modo de ação que também viria a permear as lutas pela independência do Timor no final da década de 1990.

As ações desastrosas apontaram para o fato de que Díli e a sede do governo português deveriam ser protegidas nos seus diversos flancos, e para isso o governador criou comandos militares especiais em torno da cidade, os quais permitiam um maior perímetro de proteção. Esses comandos foram reforçados por guerreiros africanos trazidos pelos portugueses para o Timor, evitando-se assim as invasões das hordas timorenses, tão comuns quando em revoltas. Esse fortalecimento militar em torno de Díli foi permitindo, aos poucos, a expansão dos comandos militares portugueses por todo o território.

Em cinco anos instalaram-se várias linhas de postos de ocupação permanente, em direções perpendiculares às costas Norte e Sul, e dominando as regiões entre Batugadé e Bobonaro, Liquiça e Hatolia, Díli e Maubisse, Manatuto e contra-costa, Baucau e Ossu, o que juntamente com Viqueque e Alas significava o estabelecimento em toda a ilha, de postos militares agrupados em comandos. De quarenta em quarenta quilômetros, estava-se seguro de encontrar um posto de oficial, sargento ou régulo fiel, com a sua guarnição, pequena é verdade, mas a que emprestava uma enorme força, moral e material, a proximidade de outros postos, e o apoio das repetidas colunas expedicionárias. (DUARTE, 1944, p. 40)

Pode-se dizer que nesse período o Timor já não gozava mais da liberdade que outrora, ainda que sob a colonização portuguesa, era 
desfrutada, pois a densa malha de comandos e postos oficiais promovia uma espécie de aperto a essas liberdades guerreiras. A percepção da perda dessa liberdade gerava pequenas revoltas por todo o território que eram prontamente contidas pela eficiente malha militar espalhada pelo Timor, de modo que tais conflitos se reduziam a pequenos movimentos insurrecionais sem dificuldade de controle.

As palavras de Duarte (1944, p. 45), ao avaliar o período de 1894 a 1900, apontam que a ocupação portuguesa, à época,

\begin{abstract}
se estendeu a todo o interior, e que as últimas revoltas anuais quase sempre insignificantes, e dominadas pelos recursos locais de cada comando, eram os estremeções epilépticos de um povo sufocando nas malhas apertadíssimas de uma organização administrativa que lhe paralisava os movimentos desordenados e atrabiliários. E tal resultado conseguiu-se sem auxílio de expedições do exterior, pois tirante a companhia desembarcada após o desastre de 1895, sempre as campanhas se fizeram com moradores de Díli e Manatuto armados de espingardas Remington e principalmente com arraiais usando azagaia e catana, pois as quinhentas espingardas não chegavam para os milhares de timores que combatiam a nosso lado hoje, para serem batidos amanhã pelos seus adversários de véspera, agora nossos aliados.
\end{abstract}

Além de brilhante estrategista militar, o governador Celestino da Silva não subestimou a inteligência e sagacidade dos liurais, ${ }^{3}$ designação usada para reis locais. Sua vivência na administração colonial na África levou-o a considerar que: "Os régulos do Timor não têm ligeira semelhança com os da África, são mais civilizados, mais inteligentes e muito menos dados aos vícios, têm muito orgulho e bem arreigado o sentimento dos seus direitos" (SILVA, 1897, p. 36). Diante dessa percepção do astucioso espírito timorense, Celestino instituiu uma rede de espionagem que incluía amantes timorenses, as quais, ao mesmo tempo também gozavam da confiança de chefes locais, funcionando como espiãs a serviço do governador. Outro ponto favorável ao domínio que se estendia aos poucos, dizia respeito à utilização por parte do governador das rivalidades entre tribos diferentes, usando inclusive o expediente, quando lhe convinha, de enfraquecer uma tribo arredia aos interesses de Portugal, fornecendo à tribo rival desta, mas amiga da coroa, provimentos com pólvora e armas

\footnotetext{
3 Afonso de Castro era da opinião de que a palavra tétum leoreay ou liurai provém da palavra portuguesa "rei". Porém, na opinião de Ximenes Belo (2013), a palavra liurai provém do termo malaio "lurah", que significa "autoridade". Os timorenses, no âmbito do comércio, tinham contatos com mercadores de Java e de Ternate (Ilhas Molucas), bem antes da chegada dos portugueses.
} 
para enfraquecimento e domínio daquela tribo inimiga. Para isso contava com sua rede de espionagem, de informação e até de desinformação, porque urdia intrigas e fomentava os confrontos. A figura de Celestino para os poderosos locais passou a possuir a mística do senhor que tudo sabe e tudo vê. Uma figura imponente que assustava a todos pelo tamanho do poder que concentrou em suas mãos. Segundo Duarte (1944, p. 65),

Celestino da Silva ficou sendo sempre para o indígena, o homem cujos olhos perscrutavam tudo e a todos, aquele para quem não havia segredos por mais bem guardados que fossem; e significativo de tal estado de espírito, é o episódio de na revolta de 1912, isto é, quatro anos após a sua exoneração, os chefes principais terem voltado às avessas, o retrato que pendia das paredes da sala dum comando que acabavam de assaltar, a fim de que os seus olhos os não incomodassem nas resoluções que iam tomar.

Após o domínio territorial militar promovido ao longo do tempo pelo governador Celestino da Silva, a empresa colonial pôde ser operada em seu viés econômico, e a atividade agrícola da cafeicultura se mostrou rentável. Todavia, o governador encontrava dificuldades para empreender o trabalho. Em situação semelhante à que a narrativa da historiografia portuguesa utilizou amiúde no Brasil para falar da indolência dos indígenas brasileiros para o trabalho na colônia, Duarte (1944, p. 67) também se utiliza desse tipo de discurso ao mencionar as próprias palavras de Celestino da Silva, nesse sentido, para o timorense:

sendo a cafeicultura uma importantíssima fonte de riqueza, e indiscutível a natural indolência dos indígenas, é indispensável que os comandos militares incitem o povo ao trabalho e forcem os régulos a cuidarem das plantações existentes improdutivas por falta de granjeio, e a fazerem outras. Se não obrigarmos estes povos ao trabalho, e os não ensinarmos, esta colônia permanecerá ainda por muito tempo no estado de atraso agrícola em que atualmente se encontra.

No campo administrativo o governador instituiu um eficiente centro de comando, diminuindo ao seu modo o poder dos prelados da Igreja - os quais em tempos anteriores concentravam tanto poder que muitas vezes derrubavam até os governadores -, mas, em função disso, granjeou fortes inimigos dentro do poder eclesiástico. Chama a atenção sua atuação no campo da educação e difusão da cultura europeia, cuja preocupação não era a popularização da educação formal no seio da sociedade timorense, mas a implantação definitiva da língua portuguesa e dos costumes europeus nas terras do Timor. Segundo Duarte (1944, p. 75), Celestino da Silva, 
Obrigava os chefes indígenas a enviar às escolas e colégios os seus filhos maiores de nove e menores de quinze anos; não consentia que nos internatos se falasse senão o português e se não vestisse senão à europeia; e os jantares mais aparatosos que em Díli se davam, eram os oferecidos pelo Governador aos chefes e régulos. Fotografias há dalguns destes indígenas, mostrando-os vestidos de sobrecasaca; a outros fazia-os seus ajudantes de campo, comandantes de postos, pilotos, comandantes interinos do vapor, secretários gerais enfim, obrigando-os desta forma a entrarem no seio da civilização.

Não obstante todo o poder que concentrou e as novas feições coloniais que havia consignado ao Timor, Celestino da Silva teve um final sem o devido reconhecimento no seu tempo. Em 1908 morreu o rei de Portugal, vitimado por um tiro, e, cinco meses depois, um decreto suspendia Celestino das funções de governador, sem um louvor, sem uma palavra de apreço. Nos termos de Duarte (1944, p. 84),

O gigante limitou-se a sorrir com amargura e desprezo, e embarcou para a Austrália, a fim de dissipar receios. Meses depois aportava a Portugal, seguia para o desterro de Almeida a comandar Cavalaria 7, e morreria em 1911, minado pelas febres, e mais ainda pelos desgostos que a ingratidão dos seus contemporâneos lhe tinha causado.

O afastamento de Celestino da Silva representou para o Timor uma espécie de refresco aos poderosos locais. Ele havia estabelecido as novas bases administrativas e militares locais. Embora tenha havido a nomeação de outros governadores sem muito destaque, posteriormente à saída de Celestino, alguns anos depois, em 1911 especificamente, há que se notar no governo de Filomeno da Câmara, que também viria a ter atuação brilhante como governador. Ele foi considerado, desde a exoneração de Celestino da Silva, como o único governador de Timor que teve posição de grande relevo. Segundo Duarte (1944, p. 85),

Logo no início do seu governo, teve de dominar a mais temerosa revolta indígena de que ali havia memória. Os chefes timorenses libertos da golilha ${ }^{4}$ que a saída de Celestino quebrara, aproveitaram-se do pretexto da elevação do imposto de capitação, para tentarem sacudir o jugo a que mal se podiam acomodar. Um oficial e vários sargentos que permaneciam no interior foram trucidados; a primeira coluna comandada pelo Governador teve um desastre sério em Aituto, vendo-se obrigada a abandonar uma peça de artilharia, vário material, e a retirar precipitadamente para Aileu. O pavor em Díli, perto do local do combate, foi enorme, pois os fatos avolumaram-se de tal modo, que davam o Governador como chacinado, e os rebeldes avançando sobre a capital.

4 Argola de ferro fixada num poste ou pelourinho, na qual se prendiam criminosos ou escravos pelo pescoço; argola. 
As notícias intempestivas levaram a população branca de Timor a embarcar no vapor "Díli" em debandada. Desfeita a boataria, a chegada de algumas companhias de soldados africanos e da Índia conduziu a situação para um caminho mais favorável. Mesmo assim, foram seis meses de luta intensa.

Manufai, o eterno fulcro de rebeliões, o histórico ninho de rebeldias foi batido e obrigado a submeter-se, sendo a mortandade tão grande, e a lição de tal maneira dura, que ela lhe serviu até agora. Apenas Okussi se manteve rebelde e foi dominado no ano seguinte, após uma campanha rápida e sem grandes lances. (DUARTE, 1944, p. 86)

A fama de bárbaro de Filomeno da Câmara se estabeleceu nessas guerras e passou a incomodar intelectuais na metrópole, influenciados com as ideias humanitárias em voga em Portugal a partir de 1910. O barbarismo se deveu ao fato de, intencionando cooptar a confiança de guerreiros timorenses para combaterem ao seu lado contra os rebeldes, Filomeno ter passado a permitir os hábitos tribais milenares dos guerreiros em se apropriar do botim dos vencidos, em degolar seus inimigos e empilharem cabeças em uma demonstração de superioridade e força. Ao final dos combates, a lúgubre pilha de crânios era ainda chutada, entoando-se cânticos, o hino guerreiro do "Lorçá" que provocava pavor nos soldados portugueses.

Mas, apesar das circunstâncias que levaram Filomeno ao controle da situação das rebeldias locais, o novo governador se notabilizou pelo fomento que deu à lavoura cafeeira com o plantio de milhões de mudas de café, que se expandiu para locais ondeantes não se cultivava, além de outras tantas experimentações de variedades em outras áreas para aclimatação. Além de café, houve uma expansão de outras culturas como o coqueiro. $\mathrm{O}$ esforço do governador fez a empresa colonial expandir-se sobremaneira, ainda que à custa do trabalho quase forçado das populações do Timor, que sob o jugo da dominação sofriam com a empresa colonial portuguesa tardia. O certo é que esse esforço do governador, após sua exoneração do cargo, não foi seguido por seus sucessores, e essas atividades econômicas, implantadas por ele, acabaram não rendendo adequadamente como se tinha planejado para um futuro próximo, quando já sem o governador. Em outros campos, ele também teve atuação destacada, como a criação da Caixa Econômica, a reforma do ensino, entre outros, que constituem o corpo de suas realizações. Deixou o governo em 1917. 
Posteriormente à sua saída, sucederam-se, no governo do Timor, administradores de curta duração que apenas se mantinham sem grandes realizações e deixavam fenecer as poucas iniciativas que uns legavam para os outros. Nesse período há destaques para alguns que contribuíram para a literatura, como foi o caso de Teófilo Duarte, que governou o Timor entre 1926 e 1928, e Álvaro da Fontoura, de 1937 a 1939. Entre os feitos desse último, está o estabelecimento em Díli, em 1938, da "Casa Portuguesa", onde era possível comprar livros, papel, tinta etc., além de ter criado um jornal denominado Timor. Porém sua maior contribuição ficou conhecida como "Álbum Fontoura",

Um valioso documentário fotográfico que mandara organizar naquela ilha e do qual constam, além de elementos importantes sobre a vida, administração, fomento, etc., da colônia, centenas de fotografias de indígenas timorenses, muitas das quais utilizáveis não só no ponto de vista estritamente etnográfico, mas sob aspecto de somatologia antropológica. (CORREIA, 1954, p. 69)

Outro governador português que merece ser citado foi Manoel de Abreu Ferreira Carvalho, que governou o Timor-Leste entre 1940 e 1945, que ficou conhecido como o governador da ocupação japonesa da Segunda Guerra Mundial. Essa ocupação, um capítulo de sofrimento e dor para a história do país, deu-se de 1942 a 1945, até a rendição dos japoneses após o lançamento das bombas atômicas pelos americanos no território japonês. É sobre esse período que trataremos a seguir.

\section{O SOFRIMENTO DO TIMOR NA OCUPAÇÃO JAPONESA DA SEGUNDA GUERRA MUNDIAL}

Sobre a ocupação japonesa de Timor, a historiografia se apresenta ambígua, pois há documentos que atestam que o país, durante essa Guerra, foi primeiro invadido pelos australianos e holandeses (FREI, 1996) que, em face da expansão japonesa pelo Pacífico, viram o Timor, por seu posicionamento geográfico, como uma área estratégica a ser defendida para evitar uma possível invasão do Japão em território australiano.

Segundo Barbedo de Magalhães (2007, p. 5),

$5 \mathrm{O}$ monumental Álbum Fontoura está disponível on-line no endereço: <https://goo.gl/ $\operatorname{avdEpB}>$. 
A maior parte dos livros publicados em Portugal sobre as ocupações de Timor Português durante a Segunda Grande Guerra descreve, por vezes com detalhe, as invasões australianas e holandesas, por um lado, e a japonesa, por outro. Descrevem, igualmente, as humilhações a que a administração portuguesa foi sujeita pelos sucessivos ocupantes e as horríveis torturas e os numerosos assassinatos de timorenses e portugueses, às mãos dos ocupantes japoneses e das colunas negras, predominantemente constituídas por habitantes de Timor Holandês e criadas, armadas e dirigidas por militares japoneses.

Mas é indiscutível que, no cenário da guerra, a cidade de Díli é descrita como tendo sido totalmente arrasada na época por bombardeios. Quem mais sofreu perdas e danos foi o povo timorense. As baixas são calculadas com base em quantitativos da população timorense antes da guerra e posteriormente, bem como na taxa de crescimento populacional asiático da época. Como a diferença desses valores representa um decréscimo populacional, ainda que se estime um valor de cerca de 20 mil pessoas que migraram para o lado ocidental da ilha (o Timor Holandês), pode-se concluir que houve acentuadas perdas por mortes. Calculam-se entre 60 mil e 80 mil timorenses mortos no período para uma população estimada de 527.00o habitantes. Para Barbedo de Magalhães (2007, p.9),

\footnotetext{
Se tomarmos como válido o número de 60.00o, em cerca de 527.00o habitantes, isso corresponderá a cerca de $11,4 \%$ da população. Se usarmos o número de 80.000 vidas perdidas, isso corresponderá a $15 \%$ da população de Timor Português. Trata-se, em qualquer dos casos, de percentagens enormes, só compatíveis às da União Soviética e da Polónia. Em termos relativos poderemos dizer, com segurança, que a população de Timor Português foi, em percentagem da população global, uma das três mais sacrificadas, em todo o mundo, na Segunda Grande Guerra, apesar de Portugal ter permanecido neutro.
}

Após a guerra e a rendição dos japoneses o território timorense retornou para o domínio colonial português. $\mathrm{O}$ mesmo não ocorreu com o território do Timor Ocidental que não retornou ao domínio colonial holandês. A Indonésia que também havia sido ocupada pelos japoneses, aproveitando-se do enfraquecimento holandês durante a Segunda Guerra em função da invasão da Alemanha Nazista à Holanda, proclamou sua independência em 1945. Com o término da guerra, a Holanda, apoiada pelas potências aliadas, empreendeu a tentativa de recuperação colonial, produzindo um conflito armado interno conhecido como Revolução Nacional da Indonésia, que durou mais de quatro anos. Nesse conflito, embora a Holanda dominasse as principais cidades, não prevaleceu no campo. Após acertos diplomáticos e por forte resistência e determinação 
da Indonésia, a revolução finalizou-se em dezembro de 1949 com o país livre (DRAKELEY, 2005). Dada a pluralidade cultural e linguística da Indonésia, que é integrada, enquanto nação, por cerca de 17 mil ilhas, das quais aproximadamente 6 mil são habitadas por populações que falam em torno de 700 línguas, o lema do país é "Unidade na Diversidade" [Bhinneka Tunggal Ika].

Essas considerações sobre a independência da Indonésia nos remetem a algo muito importante para situar o valor de que a língua portuguesa goza no território timorense e por, constitucionalmente, ter se tornado língua oficial do Timor nos tempos atuais, sobretudo como língua de instrução, o que, de certa forma, marca a identidade autônoma do país. A existência atual do Timor-Leste como nação autônoma deve-se à colonização portuguesa, pois, caso o país tivesse sido anexado à Holanda em sua expansão territorial, ainda no século XIX, certamente teria se tornado uma província da Indonésia, por ocasião da independência dela do domínio holandês - como ocorreu durante o período de invasão da Indonésia, entre os anos de 1975 e 1999. A língua portuguesa, apesar de ter sido proibida em Timor durante o período da invasão indonésia, funcionou comolíngua de resistência, com a qual a guerrilha revolucionária timorense se comunicava nesses duros anos. Possivelmente nesse ponto se encontra uma explicação plausível para a adoção da língua portuguesa, ainda que atualmente ela represente um dos grandes desafios à educação timorense.

Os sucessivos governadores portugueses que se seguiram ao pósguerra empenharam-se na reconstrução do Timor, sempre ocupando o posto por curtos períodos, alguns se dedicaram ao fomento de pequenos negócios e indústrias, sem maiores destaques na administração colonial, até o ano de 1974, quando toma posse o último governador português no Timor, o coronel Mario Lemos Pires. Aquele ano foi marcado por algumas particularidades, como a criação da primeira associação política em Timor Português, a UDT (União Democrática Timorense), nome sugerido por Ramos-Horta, ${ }^{6}$ embora o mesmo não tenha integrado o partido criado.

6 José Manual Ramos-Horta, porta-voz da resistência timorense no exílio na época da invasão indonésia, por sua luta na diplomacia internacional pela independência do Timor, recebeu o Prêmio Nobel da Paz em 1996. Tornou-se presidente do país, governando de 2007 a 2012. 


\section{UM RECORTE EDUCACIONAL NA HISTÓRIA DO TIMOR- -LESTE}

A língua portuguesa e sua implantação no Timor sempre representaram um desafio, desde as exigências que o governador Celestino da Silva fazia aos governantes locais de aprenderem a língua como condição para o exercício do poder, passando por sua proibição de uso durante o domínio indonésio até sua colocação como língua oficial de instrução na constituição de 2002, já em um país autônomo. $\mathrm{O}$ baixo prestígio da língua portuguesa no país possivelmente se deva à profusão de línguas maternas disponíveis para o uso, bem como à utilização do bahasa indonésio, que foi usado durante os vinte e cinco anos de domínio da Indonésia, além da língua inglesa, fartamente utilizada como língua de trabalho. Para a implantação da língua portuguesa, a educação do povo sempre foi vista como possibilidade, no entanto, no campo educacional, um território tão conflituoso como o do Timor, também ela passou por altos e baixos, refletindo a condução colonial por tão longo tempo.

Como mencionado, ainda no período colonial, com uma postura de maior domínio, Portugal foi efetivando uma rede administrativa composta por postos nas aldeias além de representações militares, que foram diminuindo o poder dos régulos nos seus domínios, fazendo com que estes passassem a ter um papel de intermediadores entre o povo e as autoridades coloniais. Desempenhavam funções na organização da cobrança de impostos e do repasse de homens para o serviço público, sobretudo nas guarnições militares. Os datos, ${ }^{7}$ em nível dos sucos, ${ }^{8}$ possuíam influência sobre os usos e costumes indígenas, além de participarem ativamente nos processos eleitorais dos régulos e outros chefes.

A gradual expansão dos portugueses nos mais variados setores da vida timorense foi ocorrendo de modo paulatino. Sem sobressaltos, muitas coisas foram sendo assimiladas pelos timorenses sem muita dificuldade. No contato entre os missionários católicos com os régulos de vários distritos, passou a ocorrer o convencimento de que estes enviassem seus filhos para a escola. Segundo Ximenes Belo (2013, p. 56),

7 Nobres da realeza local que exerciam funções administrativas nos distritos.

8 Suco é uma unidade político-administrativa tradicional e que, atualmente, agrega um conjunto de aldeias. Um suco corresponderia tradicionalmente a um único clã (SILVA; SIMIÃO, 2007, p. 86). Existem 498 sucos no território, numa média de 7 por subdistrito. Disponível em: <http://timor-leste.gov.tl/?p=91>. Acesso em: 16 dez. 2017. 
A partir do segundo quartel do século XIX, a pedido dos missionários e das autoridades civis, alguns régulos começaram a mandar os seus filhos para serem educados nas escolas das missões católicas. Alguns iam para Lahane e outros para Soibaba. Outros mandavam os filhos para a Escola Régia (primária) de Díli.

Dessa maneira o domínio português sobre as classes dos nobres e gradualmente dos populares em geral, não se fazia apenas pelos pactos de vassalagem que eram celebrados. Portugal sabia que a formação educacional era uma arma importante no domínio dos ânimos timorenses, desse modo, como informa Ximenes Belo (2013, p. 45),

A nível de instrução e do ensino, começaram a afluir às escolas, quer do Governo quer das Missões, jovens de todas as camadas sociais, mesmo os filhos do povo. Pouco a pouco criou-se uma nova "burguesia", ou melhor, a classe dos funcionários timorenses: os professores e catequistas, os intérpretes e escrivães, os enfermeiros, os guarda-fios, os "olheiros", isto é, os encarregados das construções (edifícios e estradas) e das plantações de café ou de palmares de coqueiros.

A instrução entre os filhos dos liurais que frequentaram as escolas missionárias e a escola masculina de Díli passou a ser um instrumento de domínio, já que muitos deles substituíram os pais, conforme estes foram morrendo, de modo que em alguns casos, o fato de saberem ler e escrever passou a ser usado como critério para exercer o poder de chefe nos sucos e aldeamentos. Segundo Ximenes Belo (2013, p. 46),

Nalguns sucos, acontecia que muitos dos novos chefes de suco não pertenciam à família dos verdadeiros liurais. Só porque "andavam na escola" e conseguiram tirar a $2^{\underline{a}}, 3^{\underline{a}}$ ou $4^{\underline{a}}$ classes, eram nomeados pelo Governo para chefes do suco. Enquanto os descendentes das casas reais que não frequentavam a escola ficaram relegados para o segundo plano. Mas, entre o povo, e, segundo os costumes ancestrais, o verdadeiro "liurai" ou "dato" é aquele que descendia dos antigos régulos, mesmo que não soubesse ler nem escrever.

Com o passar do tempo, os liurais renitentes em não enviar seus filhos para a escola, foram perdendo o prestígio e caindo em descrédito, já que, para entender os informes, as determinações do governo português, havia a necessidade de compreender a língua escrita. Nota-se nessa situação a valorização da educação para os portugueses como um sinal de superioridade civilizacional, em que as tradições e os conhecimentos mantidos na oralidade já não eram importantes. Os registros escritos e a compreensão deles representavam a forma governamental de 
administração e domínio, já que quem estava fora dessa uniformização colonial não podia compartilhar do exercício do poder.

Por isso, ao longo de várias décadas, alguns liurais, que por direito eram herdeiros do "trono" da sua casa real, tiveram de renunciar em favor dos parentes que sabiam ler e escrever. Nota-se, portanto, que, nalgumas zonas de Timor, descendentes dos verdadeiros e antigos liurais reclamam que os primos ou familiares dos seus avós foram nomeados liurais só porque "andavam na escola" e que os seus avós tiveram de renunciar porque não sabiam ler nem escrever, e não podiam, por causa disso, estabelecer contactos com as autoridades portuguesas. (XIMENES BELO, 2013, p. 57)

Essas considerações sobre a educação no universo colonial mostram-na como uma poderosa arma de mudança cultural entre os povos antigos de cultura ágrafa. A rejeição de culturas ancestrais por parte dos indivíduos bafejados pela cultura letrada é sedutora no campo da superioridade do domínio civilizacional, mas também no domínio político.

Embora sem grande participação governamental nessa empreitada, a participação dos missionários religiosos católicos na construção da educação em Timor é indiscutível, pois fundaram colégios e procederam à instrução básica, ainda que excludente. Já no final do século XIX, como aponta Figueiredo (2011, pp. 435-436),

a obra destes missionários deve ser feita em várias vertentes pelas quais se desenvolveu a sua ação. Assim, a par da instrução literária ministrada diligenciou o padre Medeiros a abertura, em Díli, de dois colégios, um masculino e outro feminino, com vista a educar rapazes e raparigas, estas últimas com o apoio do Instituto Canossiano de Macau. Com efeito, as Irmãs Canossianas estabeleceram-se em Timor com a finalidade de educar e cristianizar as mulheres indígenas, em regime de internato e externato, a quem se ensinava português, costura, lavores, música e piano. As educadas iam de todos os reinos e eram, principalmente, filhas das autoridades gentílicas. Com a fundação dos dois colégios, frequentados por filhos dos régulos e principais de toda a metade oriental da ilha, pretendia-se lançar as bases de uma sociedade "civilizada", da qual estes haviam de estar entre os principais factores de dinamização. Além de Díli, também Manatuto passou a ter uma escola feminina, muito frequentada, dirigida pelas madres canossianas, sendo algumas das suas alunas, internas.

Desde a expulsão, no século XVIII, das ordens religiosas, sobretudo dos Jesuítas, dos domínios portugueses, promovida pelo Marquês de Pombal, padres seculares assumiram a missão educadora em Timor, contando com o auxílio de religiosos de ordem. Embora essa educação se direcionasse à nobreza timorense, não era uma educação nos modelos clássicos do humanismo, pautada no conhecimento greco-romano, 
antes disso, para os homens estava voltada ao ensino de ofícios, técnicas agrícolas e administrativas, e prendas domésticas para as mulheres, ainda que nessas intenções fosse incluída a aprendizagem da leitura, da escrita e da língua portuguesa. Figueiredo (2011, p. 439) evidencia isso ao apontar que,

em 1899, para trabalhar ao lado dos padres seculares, tinham ido para a colônia alguns jesuítas. Dois deles, os reverendos Sebastião Maria Aparício da Silva e Manuel Fernandes Ferreira, fixaram-se em Soibada, onde havia uma simples missão que, em 1897 ou um pouco antes, terá sido fundada pelo padre Antonio Antunes. Os jesuítas ali edificaram, além de uma igreja, um colégio para rapazes, oficinas de pedreiro e carpinteiro, e um observatório. Os alunos, ao mesmo tempo que frequentavam a escola, onde se lhes ensinava a ler, a escrever, a contar, a falar o português, contabilidade, doutrina cristã e os princípios da moral e da educação cívica, aprendiam também os ofícios de carpinteiro, pedreiro e oleiro, e trabalhavam nas tarefas de manutenção da missão e na fábrica de sabão ali existente durante algum tempo. Em 1903, a pouca distância, foi erigido o colégio da Imaculada Conceição, feminino, entregue às Irmãs Canossianas. Cinco religiosas dirigiam um internato de mais de 60 raparigas, que ali aprendiam a instrução primária: ler, escrever, contar e música; e tarefas ligadas ao serviço doméstico: coser à mão e à máquina, fazer meia, rendas, bordar, talhar roupa, lavar e engomar, etc. Mais tarde, a montagem de uma secção de tecelagem permitia-lhes confeccionar panos e fabricar as suas roupas e as que os rapazes do colégio vizinho vestiam.

Essas iniciativas missionárias contavam com o trabalho educacional de padres estrangeiros professores vivendo em Timor, com a incumbência de ministrar esse padrão educacional à elite timorense. Porém, no ano de 1924, como informa Mendes (2005, p. 317),

D. José da Costa Nunes, bispo de Macau, cria uma escola de formação de professores primários que fossem simultaneamente catequistas. Pouco depois, surge o Colégio de Sto. António para filhos de europeus e foi reaberta a Escola de Artes e Ofícios. [...] O ensino do sexo feminino continuou nas mãos das Canossianas.

Anos depois, em 1936, o próprio Bispo de Macau criou o Seminário de Nossa Senhora de Fátima, em Soibaba, com a intenção de formar o clero timorense. A direção inicial desse seminário ficou a cargo do clero secular, sendo passada logo depois para a Companhia de Jesus. O papel desse seminário foi de grande importância na formação de uma elite intelectual que, mais tarde, viria ocupar postos-chave na administração portuguesa, ou nos cargos eclesiásticos, como foi o caso de D. Martinho da Costa Lopes e do próprio D. Carlos Ximenes Belo, prêmio Nobel da 
Paz, e de bispos de Díli. Além desses, formou também nomes importantes que se destacaram na luta pela independência de Timor, como Francisco Xavier do Amaral, primeiro presidente da Fretilin ${ }^{9}$ e do Timor-Leste, os irmãos Lobato, Nicolau e Rogério, respectivamente presidente da RDTL ${ }^{10}$ durante a ocupação indonésia e Ministro de Estado, entre outros.

Porém, a obra missionária educacional dos padres em Timor sofreria um revés durante a invasão japonesa na Segunda Guerra Mundial. No rastro da crueldade que a dominação nipônica exerceu sobre o Timor,

\begin{abstract}
os anos de invasão japonesa interromperam a actividade dos missionários, que foram ora assassinados, ora encerrados no campo de concentração de Liquiçá, tendo alguns conseguido escapar refugiando-se na Austrália. Em 4 de Setembro de 1940 havia sido criada a diocese de Díli, pela Bula Sollenibus Conventionibus. Depois da guerra foi nomeado bispo de Díli D. Jaime Garcia Goulart (1945-1966), que havia exercido as funções de Administrador Apostólico (1941-45). A acção missionária retorna então seu ritmo. O bispo reconstrói igrejas destruídas e reabre as escolas. [...] Foram então formados quatro novos colégios, um deles atribuído aos Salesianos, que se haviam fixado em Timor em 1946. (MENDES, 2005, p. 318)
\end{abstract}

Diante da dificuldade na democratização da língua portuguesa em Timor e sua baixa penetração na sociedade timorense, uma preocupação já na década de 1960 levou as missões a sugerirem uma escolarização doméstica, na tentativa de multiplicar os efeitos de uma ação educacional voltada a poucos. Segundo Mendes (2005, p. 319), esse modelo proposto,

consistia na atribuição de material didático rudimentar às famílias em que houvesse algum membro capaz de ensinar as primeiras letras às crianças, e a elaboração de um vocabulário básico Tétum-Português. Com estas duas medidas, pretendia-se expandir o conhecimento da língua portuguesa.

Em 1974, pouco antes de o processo revolucionário pela independência do Timor se efetivar, mas já bafejando os ventos dos desejos autonomistas em função da mobilização de estudantes e intelectuais - sobretudo os militantes da Fretilin que empregaram o método Paulo Freire para alfabetizar as massas camponesas -, o bispo de Díli, D. José Joaquim Ribeiro, apresentava posicionamento de hostilidade para com e viragem à

9 Frente Revolucionária de Timor-Leste Independente, partido marxista-leninista fundado ainda durante o domínio português e responsável pela resistência guerrilheira durante o período de ocupação da Indonésia.

1o República Democrática de Timor-Leste, nome oficial do país. 
esquerda que se fazia sentir e era duramente criticado por essas posturas. Na visão de Mendes (2005, p. 319), mesmo diante disso, importa sublinhar

o papel de grande relevo educativo que a Igreja e designadamente as missões tiveram na formação de um sistema educativo e de uma elite que veio a abraçar a doutrina nacionalista e sonhou um Timor independente, bem como na inculturação que fez perdurar, através da religião, a cultura e a língua portuguesas.

Nosanosquese seguiramà invasãoda Indonésia, o sistema educacional timorense passou a ser o mesmo do Estado indonésio e obrigatoriamente em idioma bahasa, sendo a língua portuguesa proibida. Embora o domínio indonésio em Timor-Leste tenha sido uma barbárie, o Estado invasor, agora tratando o Timor como sua $27^{\underline{a}}$ província, também estendeu a este território as ações de Estado. Nesse sentido, no campo educacional a Indonésia proporcionou ao Timor-Leste uma expansão que em todos os séculos de colonização portuguesa o país ainda não havia experimentado. Segundo Jones (2003, p. 41), "os portugueses deixaram o país com um sistema educacional embrionário e uma população predominantemente iletrada". Embora seja um assunto delicado a ser discutido, pois no rastro do nacionalismo que se seguiu à invasão indonésia, quase tudo que se referia ao invasor, ainda que positivo, tendia a ser desmerecido ou minimizado, é indiscutível o benefício experimentado pelo povo timorense no campo da educação sob o domínio indonésio.

Nesse sentido, o número de escolas em Timor-Leste aumentou de maneira exponencial de modo que, em 1985, havia uma escola primária em cada aldeia. Em Censo Demográfico realizado em 1995, dados apontam uma rápida melhora na alfabetização da população, sendo que 33\% das pessoas acima de 15 anos haviam completado o ensino primário. Todavia, mesmo com os esforços empreendidos, essas taxas estavam abaixo do resto do Estado indonésio que à altura contava com $65 \%$ da população nessas condições (JONES, 2003). Isso reforça a tese de que o atraso educacional sob a colonização portuguesa está refletido nesses números.

A maior fonte de orgulho para a Indonésia desde a anexação de Timor Leste em 1975 tem sido a sua oferta de educação básica. O número de escolas foi multiplicado, e cada aldeia passou a ter uma escola primária por volta de 1985 . (JONES, 2003, p. 42) $)^{11}$

\footnotetext{
11 "The greatest source of pride for Indonesia since its annexation of East Timor in 1975 has been its provision of basic education. The number of schools has multiplied, and every village had a primary school by about 1985." (Tradução nossa).
} 
Conforme tabelas a seguir, apresentadas por Jones (2003, pp. 4344), os valores incrementados pela Indonésia na educação em Timor são incontestáveis:

TABLE 1: East Timor - Trends in primary school education, 1976-93

\begin{tabular}{lccccc}
\hline School year & No. of schools & $\begin{array}{c}\text { No. of } \\
\text { teachers }\end{array}$ & $\begin{array}{c}\text { No. of new } \\
\text { pupils (000) }\end{array}$ & $\begin{array}{c}\text { Total no. of } \\
\text { pupils }\end{array}$ & $\begin{array}{c}\text { Pupils per } \\
\text { school }\end{array}$ \\
\hline $1976-77$ & 47 & 499 & 10.5 & 13.5 & 287 \\
$1977-78$ & 107 & 614 & 18.8 & 23.0 & 215 \\
$1978-79$ & 202 & 959 & 22.4 & 41.5 & 205 \\
$1979-80$ & 208 & 1610 & 13.3 & 59.1 & 284 \\
$1980-81$ & 293 & 1515 & 21.7 & 68.7 & 234 \\
$1981-82$ & 339 & 1821 & 52.1 & 77.6 & 229 \\
$1982-83$ & 376 & 2226 & 38.0 & 90.4 & 241 \\
$1983-84$ & 400 & 2446 & 38.6 & 99.4 & 249 \\
$1984-85$ & 410 & 2614 & 31.7 & 100.6 & 245 \\
$1985-86$ & 497 & 2910 & 31.3 & 111.2 & 224 \\
$1986-87$ & 540 & 3359 & 31.4 & 126.7 & 235 \\
$1987-88$ & 559 & 3723 & 27.2 & 129.6 & 232 \\
$1988-89$ & 565 & 4894 & 27.9 & 105.1 & 186 \\
$1989-90$ & 574 & 4739 & 20.9 & 100.4 & 175 \\
$1990-91$ & 559 & 4574 & 28.9 & 95.9 & 171 \\
$1991-92$ & 590 & 4653 & 21.1 & 104.4 & 177 \\
$1992-93$ & 654 & 5260 & 24.1 & 110.6 & 169 \\
$1993-94$ & 652 & 6656 & 27.4 & 128.0 & 196 \\
\hline
\end{tabular}

Source: Timor Timur Dalam Angka (1993:Table 4.1.3).

Figura 1: Dados da evolução do número de escolas, professores e alunos do ensino primário em Timor-Leste no período 1976-1993.

Fonte: Jones (2003, p. 43). 
Remate de Males, Campinas-SP, v. 38, n. 1, pp. 240-267, jan./jun. 2018 - 263

TABLE 2: East Timor - Trends in secondary and tertiary education, 1976-93

\begin{tabular}{lccccc}
\hline School year & $\begin{array}{c}\text { No. of lower } \\
\text { secondary } \\
\text { schools }\end{array}$ & $\begin{array}{c}\text { No. of lower } \\
\text { secondary } \\
\text { students }\end{array}$ & $\begin{array}{c}\text { No. of upper } \\
\text { secondary } \\
\text { schools }\end{array}$ & $\begin{array}{c}\text { so. of upper } \\
\text { secondary } \\
\text { students }\end{array}$ & $\begin{array}{c}\text { No. enrolled } \\
\text { in tertiary } \\
\text { education }\end{array}$ \\
\hline $1976-77$ & 2 & 315 & - & - & - \\
$1977-78$ & 9 & 926 & - & - & - \\
$1978-79$ & 14 & 1041 & - & - & - \\
$1979-80$ & 15 & 1248 & - & 64 & - \\
$1980-81$ & 19 & 2474 & 1 & 225 & - \\
$1981-82$ & 23 & 4272 & 1 & 454 & - \\
$1982-83$ & 28 & 5453 & 2 & 977 & - \\
$1983-84$ & 35 & 8247 & 2 & 1541 & - \\
$1984-85$ & 43 & 9836 & 2 & 2770 & - \\
$1985-86$ & 57 & 11735 & 7 & 5310 & 443 \\
$1986-87$ & 71 & 22905 & 17 & 7599 & 675 \\
$1987-88$ & 81 & 26787 & 19 & 10889 & 799 \\
$1988-89$ & 90 & 28342 & 22 & 10088 & 969 \\
$1989-90$ & 90 & 28964 & 31 & 14574 & 1210 \\
$1990-91$ & 94 & 31482 & 35 & 19634 & 1383 \\
$1991-92$ & 97 & 24261 & 38 & 17177 & 2037 \\
$1992-93$ & 101 & 21972 & 42 & 17947 & 2199 \\
$1993-94$ & 103 & 21779 & 43 & 18303 & 2658 \\
\hline
\end{tabular}

Source: Timor Timur Dalam Angka (1993:Tables 4.1.4, 4.1.6, 4.1.7, 4.1.23, 4.1.55).

Figura 2: Dados da evolução do ensino médio e ensino superior em Timor-Leste no período 1976-1993.

Fonte: Jones (2003, p. 43).

Os números acima por si só bastam para servir de contraste com o que Portugal deixou de herança no sistema educacional. Todavia, esses ganhos educacionais não perduraram no tempo. A crise instalada com o processo de independência a partir de 1999 levou à quase total destruição física das escolas e dos documentos das mesmas. As milícias pró-Indonésia não pouparam essa estrutura educacional montada pelo Estado indonésio durante a ocupação. Aliado a isso, com o início da independência do Timor-Leste, a opção pela língua portuguesa e pelo tétum para a instrução possivelmente reduziu esses ganhos a quase zero, pois, como a quase totalidade dos professores eram indonésios ou timorenses formados na Indonésia, com a autonomia a maior parte deles se retirou para este país, produzindo um "vazio" educacional que começou a ser preenchido a partir das missões de cooperação internacional no campo da educação, conduzidas, sobretudo, por Portugal e Brasil a partir de 2002. 


\section{CONSIDERAÇÕES FINAIS}

Na contemporaneidade políticas para o fortalecimento da instrução básica primária em línguas maternas no Timor se fazem presentes, sob o argumento de que, se as crianças não aprenderem em suas línguas maternas no ensino primário, certamente em pouco tempo essas línguas desaparecerão, pois não possuem um fortalecimento por meio de uma literatura que as estabeleça no meio social. Isso faz diminuir ainda mais o espaço da língua portuguesa na infância. A falta de imersão total no português na escola também enfraquece o seu prestígio. Relegada à exposição de poucas horas semanais na organização pedagógica curricular escolar, a língua portuguesa acaba não sendo cultivada pelas crianças no espaço educacional. Ao retornarem para seus lares também não exercitam na família, que quase sempre prefere as suas línguas maternas na comunicação cotidiana.

Dentro dessa perspectiva, embora o Timor-Leste faça parte da Comunidade dos Países de Língua Portuguesa (CPLP), provavelmente é o país com o mais baixo número de falantes na Comunidade. O português é falado por uma elite, composta em sua maioria por professores universitários, funcionários públicos, políticos, intelectuais e pessoas mais velhas. Por outro lado, o plurilinguismo que de fato marca a identidade do timorense se fortalece e ganha evidência, pois ele naturalmente é um poliglota, falando no mínimo três línguas - o tétum, sua língua materna, mais o bahasa indonésio ou o inglês, quando não as duas últimas, estando o português sempre em segundo plano na preferência de aprendizagem ou de uso.

Mas um fenômeno é notável em Timor: todos os que completam seu ciclo de escolarização até o nível superior, nas graduações e nas pós-graduações, aprendem o português, por uma simples razão: boa parte da bibliografia utilizada nos cursos, ou está em português ou em inglês, o que leva o estudante universitário a aprendê-las. Assim, uma possível identidade timorense como falantes definitivos da língua portuguesa talvez venha a ser estabelecida quando houver a universalização do acesso ao nível superior das novas gerações. O tamanho do desafio para alcançar essa meta pode ser dimensionado ao se observar que a população atual com 15 anos ou mais que sabe ler e escrever em Timor, segundo dados obtidos na Cia. World Factbook, Central Intelligence Agency (2017), é de $67,5 \%$. A título de comparação, segundo a mesma fonte, o Brasil apresenta 92,6\% para a mesma faixa etária especificada. 
Sem muito esforço, a conclusão vem fácil diante do que se viu acima. O alcance de um Timor-Leste com identidade cultural como nação que possui como língua de herança o português e características culturais dele, passa pela aquisição da escolarização. O que a princípio se faz para a aquisição da língua em função de uma literatura mais técnica voltada para a formação superior, será também a porta de entrada para a riqueza literária que o português possui. Se por um lado o Timor-Leste se orgulha da sua autonomia como nação independente, geopoliticamente no coração da Indonésia, devendo essa condição à língua portuguesa, por outro, ao analisarmos a sua história percebemos o desprezo que Portugal conferiu a esse território durante seu domínio colonial, sobretudo no campo da educação, o que enfraqueceu a aquisição dos aspectos culturais lusitanos. A aquisição da língua portuguesa representou e representa um obstáculo - ao desenvolvimento educacional, já que, como língua de instrução, segundo a Constituição, não goza de prestígio no país, sendo preterida diante das outras tantas disponíveis -, mas torna-se claro que a chave para o estabelecimento definitivo da influência, ainda que tardia, do outrora vasto Império Lusitano no Índico, e especificamente em Timor, dar-se-á pela educação.

\title{
THE CHALLENGE OF THE CURRENT EAST TIMOR: IN SEARCH OF A NATIONAL IDENTITY LINKED TO THE PORTUGUESE LANGUAGE
}

\begin{abstract}
A product of extensive research on education in East Timor, this article represents a clipping about the challenges of implementing the Portuguese language in that country that has placed it as an official language of instruction in its Constitution. Timor is considered a transcontinental country for presenting its dominions both on the Asian continent in its northern portion on the influence of the Pacific, and in Oceania in its southern portion linked to the Indian Ocean. An old Portuguese colony, probably the least prestigious of the Portuguese overseas empire, has its history fraught with challenges in search of its autonomy as a nation. The objective of this work is to present, through the narratives of Portuguese colonial rulers in Timor of the colonial period, Afonso de Castro (1824-1885) and Teófilo Duarte (1898-1958), the difficulties of the Portuguese colonial enterprise in those lands in face of their plurality linguistic and cultural, the spirit of their inhabitants in relation to the Portuguese domain and the obstacles to the definitive implantation of the colonial enterprise conferred by the distance from the metropolis. For this, a bibliographical research was carried out on books and documents in the Library of the Postgraduate Research Program (PPGP) of the National University of Timor Lorosa'e (UNTL) in Dili, East Timor, as well as the Library of the National Institute of Training of Teachers and Professionals of Education (Infordepe), interviews with teachers and teacher trainers and students in the country. As a result, it is possible to identify the difficulty in
\end{abstract}


the implantation of the Portuguese language through the educational route due to the lack of immersion in this language in the school space, the great offer of mother tongues for daily communication, the strengthening of movement for the implantation of mother tongues in schooling of the children while pointing out the possibility of acquiring the Portuguese language by its people through the reach of the complete cycle of schooling at a higher level.

Keywords: East Timor; portuguese colony; portuguese language.

\section{REFERÊNCIAS}

BARBEDO DE MAGALHÃES, António. Timor-Leste - Interesses internacionais e actores locais. V. I: Da invasão australo-holandesa à decisão australo-indonésia de anexar, 1941-1974. Porto: Edições Afrontamento, 2007.

CASTRO, Afonso de. As possessões portuguezas na Oceania. Lisboa: Imprensa Nacional, 1867 .

CORREIA, António A. Mendes. Timor português, contribuição para o seu estudo antropológico. Lisboa: Imprensa Nacional de Lisboa, 1954.

DRAKELEY, Steven. The History of Indonesia. Londres: Greenwood Press, 2005.

DUARTE, Teófilo. Ocupação e colonização branca de Timor. Coleção Fórum - Estudos Coloniais, 13. Secção, n. 2. Porto: Editora Educação Nacional, 1944.

FIGUEIREDO, Fernando Augusto. Timor, a presença portuguesa (1769-1945). Lisboa: Centro de Estudos Históricos - Universidade de Lisboa, 2011.

FREI, Henry. Japan's Reluctant Decision to Occupy Portuguese Timor, 1 January 1942/ 20 February, 1942. Australian Historical Studies, n. 107, out. 1996. Disponível em: <http://dx.doi.org/10.108o/10314619608596014>. Acesso em: 10 ago. 2016.

JONES, Gavin W. East Timor: Education and Human Resource Development. In: FOX, James J.; SOARES, Dionisio Babo (Orgs.). Out of the Ashes Destruction and Reconstruction of East Timor. Camberra: Publisher ANU e Press, 2003.

MENDES, Nuno Canas. A "Multidimensionalidade" da construção identitária em Timor-Leste: nacionalismo, Estado e identidade nacional. Lisboa: Instituto Superior de Ciências Sociais e Políticas - Universidade Técnica de Lisboa, 2005.

SILVA, José Celestino. Relatório de Operações de Guerra no districto de Timor no anno de 1896. Lisboa: Imprensa Nacional, 1897.

SILVA, Kelly Cristiane da; SIMIÃO, Daniel Schroeter (Orgs.). Timor-Leste por trás do palco: cooperação internacional e a dialética da formação do Estado. Belo Horizonte: Editora UFMG, 2007. 
Remate de Males, Campinas-SP, v. 38, n. 1, pp. 240-267, jan./jun. 2018 - 267

THE WORLD Factbook. East Timor. CIA - Central Intelligence Agency (site). EUA. Disponível em: <https://www.cia.gov/library/publications/the-world-factbook/ geos/tt.html>. Acesso em: 20 nov. 2017.

XIMENES BELO, Dom Carlos Filipe. Os reinos antigos de Timor-Leste: reys de Lorosay e reys de Lorothoba, coroneis e datos. Porto: Editora Porto, 2013. 